Research report

\title{
Is it valid to measure suicidal ideation by depression rating scales?
}

\author{
Martin Desseilles ${ }^{\text {a,b,c,*,1 }}$, Nader Perroud ${ }^{\mathrm{d}, 1}$, Sébastien Guillaume ${ }^{\mathrm{e}}$, Isabelle Jaussent ${ }^{\mathrm{e}}$, \\ Catherine Genty ${ }^{\mathrm{e}}$, Alain Malafosse ${ }^{\mathrm{d}, \mathrm{f}}$, Philippe Courtet $^{\mathrm{e}}$ \\ a Cyclotron Research Centre, University of Liège, Belgium \\ b Depression Clinical and Research Program, Department of Psychiatry, Massachusetts General Hospital, Harvard Medical School, Boston, MA, USA \\ c Laboratory for Neurology and Imaging of Cognition, Department of Neuroscience, University of Geneva, Switzerland \\ d Department of Psychiatry, University of Geneva Medical School, Geneva, Switzerland \\ e Université Montpellier 1, France; Inserm U888, Montpellier, France; Department of Emergency Psychiatry, Montpellier, France \\ f Psychiatric Genetic Unit, Division of Medical Genetic, Department of Medical Genetic and Laboratories, University Hospitals of Geneva, Switzerland
}

\section{A R T I C L E I N F O}

Article history:

Received 22 June 2011

Received in revised form 7 November 2011

Accepted 14 November 2011

Available online 10 December 2011

\section{Keywords:}

Suicidal ideation

Suicide

Depression

Beck Depression Inventory

Hamilton Depression Rating Scale for

Depression

Scale for Suicide Ideation

\begin{abstract}
A B S T R A C T
Objective: To date, most researchers rely on suicidal items of scales primarily designed to measure depression severity to capture suicidal ideation (SI). This study aims at investigating how well the suicide item of the clinician rated Hamilton Scale for Depression (HAM-D) and principal factors derived from this scale correlate with SI scores derived from a well validated measure of SI: the Beck's scale for SI (SSI).

Method: 281 suicide attempters consecutively hospitalized between 2007 and 2009 were assessed by using the SSI, the HAM-D and the self-report Beck Depression Inventory (BDI). Principal Component Analysis (PCA) was computed to extract main factors. Correlations between these factors, BDI's and HAM-D's suicide items and the SSI scores were then computed. Results: Three components were derived from the PCA. Factor 2 showed a major loading for the HAM-D suicide item. Both the HAM-D suicide item and Factor 2 positively correlated with the SSI total score (both $\mathrm{p}<0.00001$ ). Moreover, the BDI suicide item highly correlated with the Factor $2(p<0.001)$ and the SSI total score $(p<0.00001)$. Finally, the HAM-D suicide item correlated significantly with the number of suicide attempts $(p=0.0001)$ and the age at the first attempt $(\mathrm{p}=0.002)$.

Limitations: Our sample was heterogeneous and future studies should refine the taxonomy of the suicidal behavior in specific sub-populations. The study design was cross-sectional and replication in a prospective study is needed.

Conclusion: These findings suggest that the use of a single suicide item or a dimensional factor derived from a depression scale might be a valid approach to assess the suicidal ideations. Moreover, the results suggest that clinician rated scales as well as self-report questionnaires are equally valid to do so.
\end{abstract}

(c) 2011 Elsevier B.V. All rights reserved.

\section{Introduction}

Suicide is a major public health problem and a leading cause of death worldwide. Approximately $13.5 \%$ of the U.S.

* Corresponding author at: Cyclotron Research Centre, University of Liège B30, 8 Allée du 6 Août, B-4000 LIEGE, Belgium. Tel.: + 1617681 7082; fax: + 3243662946 .

E-mail address: m.desseilles@ulg.ac.be (M. Desseilles).

1 Authors participated equally to this works. population has experienced suicidal thoughts or whishes at some point in their lives, $3.9 \%$ a plan, and $4.6 \%$ an attempt. The National Comorbidity Survey showed that cumulative probabilities were $34 \%$ for the transition from ideation to a plan, $72 \%$ from a plan to an attempt, and $26 \%$ from ideation to an unplanned attempt. In addition, about $90 \%$ of unplanned and $60 \%$ of planned first attempts occurred within 1 year of the onset of ideation (Kessler et al., 1999). Another recent survey in 84850 adults of 17 countries showed that across all countries, $60 \%$ of transitions from ideation to plan 
and attempt occur within the first year after ideation onset (Nock et al., 2008).

In this context, an accurate and reliable measure of suicidal ideations appears to be important for the prediction of a subsequent attempt. However, although a vast literature on correlates and risk factors for suicidal acts exists, prospective studies failed to predict even one suicide (Goldstein et al., 1991), with a few exceptions for two long term prospective studies (Brown et al., 2000; Oquendo et al., 2004). There might be several causes for this. The first possible cause is the low base rate of suicide. Another reason might be that patients deny suicidal thoughts in their last verbal communications before killing themselves (Busch et al., 2003). A third possible cause might be the lack of refinement of indices derived from clinical scales that might fail to capture the potential ongoing suicide processes.

Important clinical issues such as suicide ideation require specific evaluation and, provided the problem was recognized before, a suitable rating scale will already exist. What is being measured? Is a rating scale most appropriate? Is the scale to be used more than once to measure change? Is the scale to be used for rating symptoms? All these questions should underlie the selection of the proper scale. In clinical practice, although the Hamilton Depression Rating Scale (HAM-D) was developed for use with psychiatric inpatients diagnosed with unipolar and bipolar affective disorder, it became the most common scale used in treatment trials on depressed outpatients (Bagby et al., 2004; Elkin et al., 1989) and is widely used for clinical evaluation of patients arriving in a psychiatric emergency setting, at least in Europe. A couple of recent pharmacogenetic studies used the 'suicide' item of Hamilton's, Beck's or Montgomery-Asberg's depressive scale in order to assess the suicidal ideations associated with antidepressant treatment in the context of clinical trials (Perroud, 2011; Perroud et al., 2009a, 2009b, 2010). However, there is no direct evidence that a single item 'suicide' correlates with a gold standard clinical evaluation of suicide ideation such as the score at the Beck's Scale for Suicide Ideation (SSI) (Beck et al., 1979). Furthermore, there is some evidence for a dimensional approach of depressive symptoms using factorial analysis, rather than a categorical approach (Korszun et al., 2004). This question has been addressed by using Principal Component Analysis (PCA) (Shafer, 2006) and a three-factor solution was derived from several depression scale (Uher et al., 2008). Interestingly, this approach revealed a factor loading mainly for suicide ideation suggesting that a widely used depression scale might measure efficiently the suicidal ideation.

The present study had several purposes. The first was to expand on past research by examining the link between a factor derived from HAM-D PCA and loading mainly for suicide and the suicide ideations derived from SSI. The second aim was to validate the use of a single item 'suicide', measured by scales primarily designed to measure depression, in the evaluation of suicide ideation by examining the correlation between single item and the SSI. Finally, the study addressed the important question of how clinician rating scales differ from self-report measures on this particular question.

\section{Material and method}

\subsection{Population}

281 suicide attempters aged between 18 and 83 years ( mean $=41.16$; $\mathrm{SD}=13.6$ ) were recruited following a hospitalization for either a suicide attempt $(n=200)$ or any other psychiatric reason $(n=81)$ from the Department of Emergency Psychiatry of the Montpellier University Hospital between 2007 and 2009. All the subjects were thus outpatients admitted to the emergency room for clinical care during a suicidal crisis; several of them were hospitalized, and thus became inpatients. The assessment was realized at admission to the emergency room by 3 qualified raters, diminishing thus the inter-raters variability. Subjects were assessed for psychiatric diagnoses using the French version of the Mini International Neuropsychiatric Interview (MINI Sheehan et al., 1998). The protocol was approved by the research ethics committee of the Faculty of Medicine of the University of Montpellier. All participants gave their written informed consent before inclusion in the study.

\subsection{Assessment}

At the time of inclusion, in addition of questions on data for number of attempts and age at first attempt, the following clinician and self-report assessments were used (Table 1):

\subsubsection{Hamilton Depression Rating Scale-17 items (HAM-D17)}

The Hamilton Depression Rating Scale (HAM-D17) is the 17-item version of a scale used to assess the range of depressive symptoms including depressed mood, work and activities, sleep, suicidal thinking, psychomotor agitation/ retardation, appetite, sexual interest, anxiety, somatic symptoms, and cognitive symptoms (Hamilton, 1960). The items on the HAM-D17 are rated on a scale of $0-2$ or $0-4$, with higher scores being more severe (e.g., item 3: Suicide: $0=$ absent, $1=$ Feels life is not worth living, $2=$ Wishes he were dead or any thoughts of possible death to self, $3=$ suicidal ideas or gesture, $4=$ attempts at suicide).

\subsubsection{Beck Depression Inventory-Short Form (BDI-SF)}

The Beck Depression Inventory (BDI) (Beck et al., 1961) is a widely used self-rating scale for measuring depression. The $\mathrm{BDI}$ is divided in two subscales: the cognitive-affective (items

\section{Table 1}

Means, Standard Deviations (SD) and range for the HAM-D17 (Hamilton Depression Scale for Depression-17 items), the SSI (Beck's Scale for Suicidal Ideation), and the BDI-SF (Beck Depression Inventory Short Form). Note. $\mathrm{n}=$ number of subjects who completed the scales.

\begin{tabular}{lll}
\hline Variable & $\mathrm{n}$ & $\begin{array}{l}\text { Mean } \pm \text { SD } \\
\text { (range) }\end{array}$ \\
\hline Age & 281 & $\begin{array}{l}41,16 \pm 13,65 \\
(18-83)\end{array}$ \\
HAM-D17 & 281 & $11,82 \pm 6,29$ \\
& & $(1-35)$ \\
BDI-SF & 191 & $16,96 \pm 8,51$ \\
& & $(0-36)$ \\
SSI & 281 & $2,18 \pm 2,76$ \\
& & $(0-10)$ \\
\hline
\end{tabular}


1 to 13 ) and the somatic-performance (items 14 to 21) (Beck and Steer, 1993). The cognitive-affective subscale alone, the so-called BDI short-form (BDI-SF), was proposed to assess depression in the medically ill subjects with scores higher than 10 associated with moderate and severe depressive syndromes (Beck and Beck, 1972).

\subsubsection{Scale for Suicide Ideation (SSI)}

The Scale for Suicide Ideation (SSI) is a clinician-rating scale and is presented in a semi-structured interview format (Beck et al., 1979). It consists of 19 items that evaluate three dimensions of suicide ideation: active suicidal desire, specific plans for suicide, and passive suicidal desire. Each item is rated on a 3-point scale from 0 to 2; the higher the total score, the greater the severity of suicide ideation. In some previous studies on adult suicidality a score of 6 or more has been used as a cutoff threshold for clinically significant suicidal ideation (Sokero et al., 2003). While the 19-item SSI (Beck et al., 1979) was used to evaluate the current intensity of the patients' specific attitudes, behaviors, and plans to commit suicide, the first 5 items are used to screen for attitudes toward living and dying, and only patients who report a desire to make an active (item no. 4) or passive (item no. 5) suicide attempt are rated on items no. 6-19 (Beck et al., 1997).

\subsection{Statistical analysis}

Statistical analyses were conducted using the Statistical Package for the Social Sciences (SPPS) (SPSS Inc. SPSS Version 14.0 Chicago, SPSS Inc, 2005).

\subsubsection{Principal Component Analysis (PCA)}

We computed Principal Component Analysis (PCA) (Shaw, 2003) to extract the main factors ('psychometric constructs') characterizing the population's variance over the 17 items of the HAM-D17 (Fig. 1). This approach is similar to those of Uher et al. (2008). We chose to compute a PCA on the HAM-D17 because we were primarily interested in this scale and because it was the depression scale filled out by

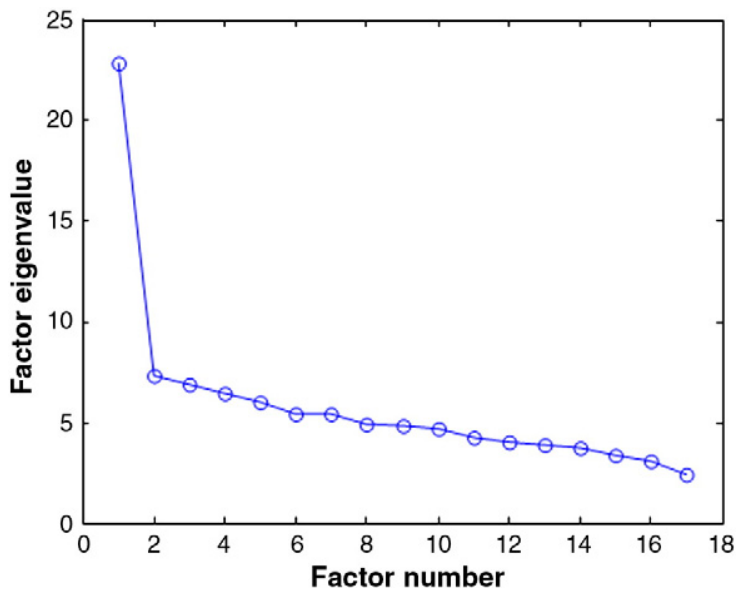

Fig. 1. Exploratory factor analysis eigenvalues for the HAM-D17. The first factor accounts for $22.84 \%$ of total HAM-D17 variance. The second factor accounts for $7.36 \%$ of total HAM-D17 variance. The third factor accounts for $6.92 \%$ of total HAM-D17 variance. all 281 patients. The results of a PCA are typically discussed in terms of component scores (factors explaining the distribution of the population's variance over the variables included in the analysis, also called eigenvectors) and loadings (contributions of the different variables to each factor) (Shaw, 2003). The two main advantages of this approach are (1) to separate orthogonal components across multiple response items and (2) to provide a robust summary profile for each component across all items. PCA was performed on a matrix constituted by the 17 items of the HAM-D17 in the number of depressed patients (matrix of $17 \times 281$ with 281 patients). We used the first three PCA components of the HAM-D17 as regressors in a multiple regression analysis with the first five items of the SSI and the sum of the five items.

\section{Results}

Means, Standard Deviations (SD) and range of total score of HAM-D17, BDI-SF, and SSI are displayed in Table 1. Out of the 281 subjects, 85 (30.2\%) male patients recruited, 76 made a suicide attempts in the week preceding admission, 124 between 1 week and 1 month, 24 between 1 month and 6 months, 5 between 6 months and 1 year, and 52 more than one year previously. The mean age at first suicide attempt was $34.2(\mathrm{SD}=15.1), 46(16.4 \%)$ patients made a violent suicide attempt, and the mean number of suicide attempts was 2.45 (SD=2.34). $189(67.2 \%)$ of the subjects suffered from major depressive disorder, 82 (29.2\%) from bipolar disorder and 10 (3.6\%) from other disorders (anxiety and substance use disorders).

\subsection{Principal Component Analysis}

The 3 first components resulting from the PCA of the HAM-D17 are displayed in Fig. 2. The first component accounted for $22.84 \%$ of total HAM-D17 variance and showed a major loading of items 1,7 , and 10 , respectively 'depressed mood', 'work and activities', and 'psychological anxiety'. The second component accounted for 7.36\% of total HAM-D17 variance and showed a major loading of item 3 'suicide' and item 7 'work and activities'. The third component accounted for $6.92 \%$ of total HAM-D variance and showed a major loading of item 3,4,5, and 6, respectively 'suicide', 'insomnia early', 'insomnia middle', and 'insomnia late' (Fig. 2).

3.2. Regressions analysis with the first and third Factors of the HAM-D17

Factor 1 showed a significant correlation with the number of depressive episodes $(r=0.17 ; p=0.018)$. There was no significant correlation between Factors 1 and 3 and the sum of the five first items of the SSI. Factor 3 significantly correlated with the suicide item of the HAM-D17 $(r=0.216$; $\mathrm{p}=0.0002$ ) but not with the suicide item of the BDI-SF.

\subsection{Regressions analysis with the second Factor of the HAM-D17}

The correlations between Factor 2 and the first five items of the SSI at the same interview were all highly significant as was the correlation between the Factor 2 and the sum of the 


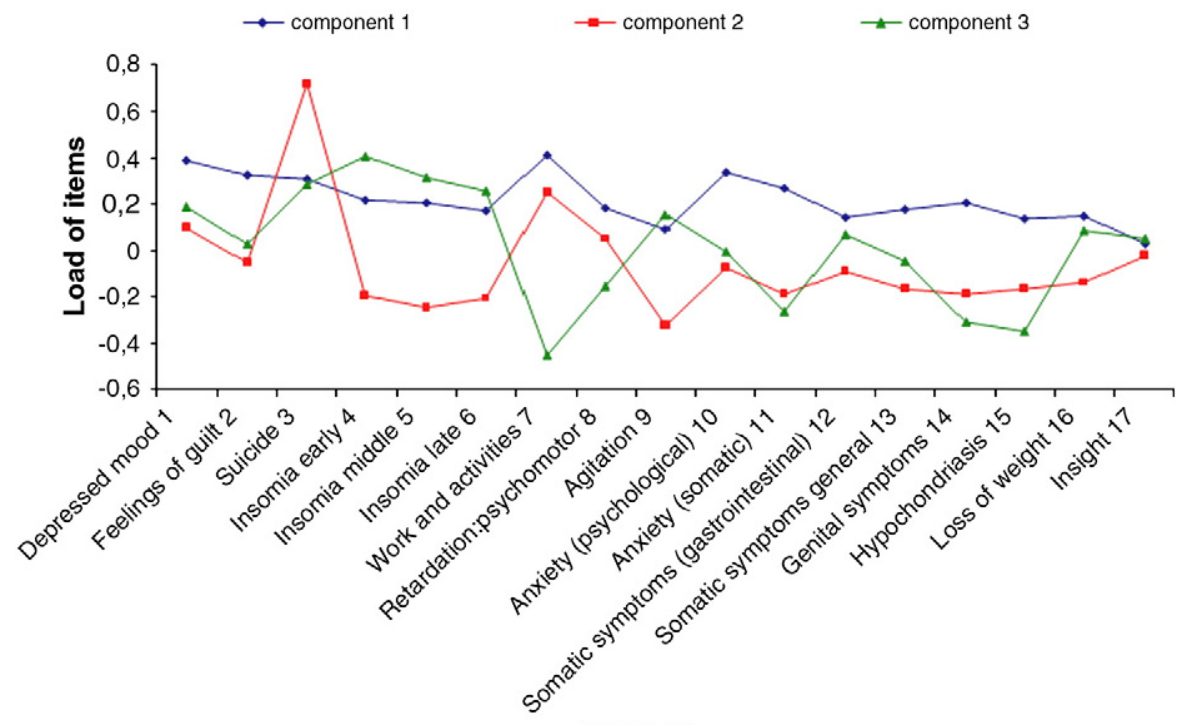

HAM-D items

Fig. 2. Three first components resulting from the Principal Component Analysis of the Hamilton Depression Rating Scale 17 items at admission. Figure displays items of the HAM-D17 ( $x$ axis) and the loadings of each items ( $y$ axis) in the contribution of the component score. A (blue line, diamonds) First component, accounting for 22.84\% of total HAM-D17 variance, showing a major loading of items 1, 7, and 10, respectively 'depressed mood', 'work and activities', and 'psychological anxiety'. B (red line, square) Second component, accounting for 7.36\% of total HAM-D17 variance, showing a major loading of item 3 'suicide'. C (green line, triangle) Third component, accounting for 6.92\% of total HAM-D17 variance, showing a major loading of item 3, 4, 5, and 6, respectively 'suicide', 'insomnia early', 'insomnia middle', and 'insomnia late'.

five items of the SSI (Table 2 and Fig. 3). Of note, the correlation between the sum of the five first items of the SSI and item suicide of the HAM-D17 was also significant $(r=0.55$; $\mathrm{p}<0.00001$ ).

3.4. Correlations between suicide item of the BDI-SF and the second Factor of the HAM-D17 and the SSI

The correlations between the suicide item of the BDI-SF and Factor $2(\mathrm{r}=0.22 ; \mathrm{p}<0.001)$ or the sum of the first five items of SSI $(\mathrm{r}=0.48 ; \mathrm{p}<0.00001)$ were also highly significant.

\subsection{Age at first suicide attempt and number of suicide attempts}

The correlation between Factor 2 and the number of suicide attempts or the age of the patient at the first attempt was not significant. However, the item suicide of the HAM-D17 significantly correlated with the number of suicide attempts $(r=0.23 ; p=0.0001)$ and significantly correlated with the age of the patient at the first attempt (inverse correlation: $\mathrm{r}=-0.18 ; \mathrm{p}=0.002$ ). The suicide item of the BDI-SF correlated with the age of the patient at the first attempts (inverse correlation: $r=-0.17 ; p=0.013$ ) but not with the number of suicide attempts.

\section{Discussion}

The results of the present study showed that a single item and/or a dimensional factor derived from a scale primarily designed to measure depression severity compares favorably with the 'screening portion' of the gold standard for measuring suicidal ideation (SI): the SSI. In addition, the correlation between the suicide item of the BDI and the first 5 items of the SSI is encouraging. Results for the suicide item of the HAM-D17 and the first 5 items of the SSI would be of interest, since this single item is one of the most commonly used in the literature. The present results also highlight that both self-report questionnaires and clinician rated-scales might be equally effective to assess SI.

The PCA results revealed three main sub-factors loading respectively for depression (items: depressed mood, work and activities and psychological anxiety), suicide ideation (items: suicide and work and activities) and sleep disturbances (suicide, insomnia early, insomnia middle, and insomnia late). Our results at baseline are similar to those of Uher et al. (2008) who did a cross-sectional study in 660 adult patients with unipolar depression (Uher et al., 2008). In their study they found three factors they called 'observed mood and anxiety' factor (loading for clinician-rated anxiety, mood, and activity items), 'cognitive' factor (loading for suicide and guilt), and 'neurovegetative' factor (loading for appetite, weight loss, sleep and sexual drive). However, the

Table 2

Correlations between Factor number 2 from the HAM-D17 PCA and items of the SSI.

\begin{tabular}{llllll}
\hline Variable & SSI item 1 & SSI item 2 & SSI item 3 & SSI item 4 & SSI item 5 \\
\hline Factor 2 HAM-D & $\mathrm{r}=0.39 ;$ & $\mathrm{r}=0.34 ;$ & $\mathrm{r}=0.34 ;$ & $\mathrm{r}=0.28 ;$ \\
& $\mathrm{p}<0.00001$ & $\mathrm{p}<0.00001$ & $\mathrm{p}<0.00001$ & $\mathrm{p}<0.00001 \quad \mathrm{r}=0.40 ;$ & $\mathrm{p}<0.00001 \quad \mathrm{p}<0.00001 \quad$ \\
\hline
\end{tabular}




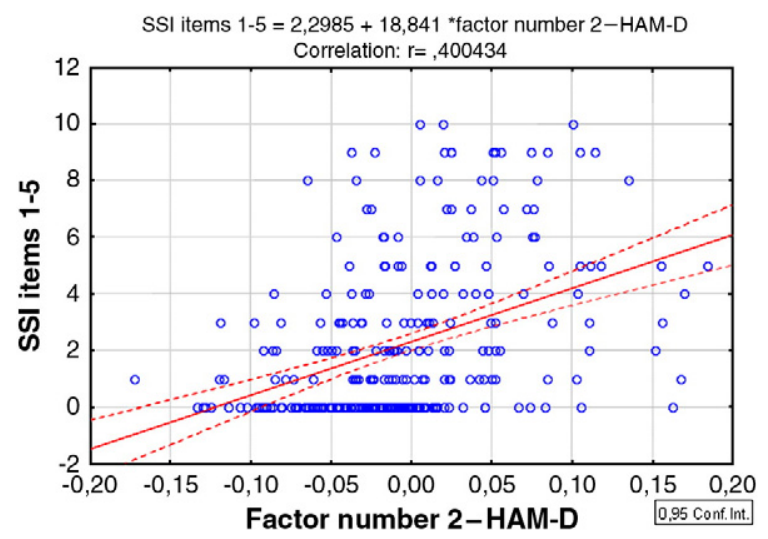

Fig. 3. Correlation between the Factor 2 of HAM-D17 Principal Component Analysis and the sum of the first 5 items of the Scale of Suicide Ideation.

sample studied in the present study might have been different since all of the patients included here had made a suicide attempt. This particular sample might explain the prevalence of the suicide item in the second component as well as its presence in the third component with sleep disturbances.

The correlation between Factor 1 and the number of episodes is congruent with the literature that links the severity of depression with recurrence risk (Melartin et al., 2004). These results suggest that the higher the number of episodes, the more severe is the depression, or reciprocally, the more severe the depression, the higher is the recurrence. In both situations, this observation should influence clinical decision regarding the need for maintenance therapy.

We here found that the use of a single item suicide derived from depression scale is a valid approach to assess suicidal ideations, congruently to the suggestion of Wenzel Brown and Beck (Wenzel et al., 2008, p. 29). In addition, Brown (2002) suggested that these scales may provide only limited information of suicide-related behavior because they only contain single suicide items. Indeed, we agree that the provided information is only useful to assess suicidal ideation, and not directly suicidal behavior.

Our results also revealed that the second factor, loading mainly for suicide correlated significantly with the suicide item of the HAM-D17 or the BDI-SF and also with each of the five first items of the SSI. These results suggest that suicidal ideation could be screened efficiently by using the second factor of the HAM-D17 PCA. The advantage of using the factorial analysis is that it provides a robust summary profile for each component across all items, i.e. it takes into account all items either positively or negatively and not only one item. By separating orthogonal components across multiple response items it allows the refinement of the core depressive facets in the population studied that can be used as regressors in correlation analysis. These results are of importance given the recent controversies about the assessments of antidepressant-related suicidal ideation in clinical trials (Meyer et al., 2010). We here propose that suicide items of or factor derived from scales primarily designed to measure depression severity from both self-report of clinician-rated scales are valid way to assess suicidal ideation and could be used confidently in clinical trials.
While the Factor 3 loaded also for suicide, it did not correlate with SSI and is not likely to represent a 'suicide ideation' component but more a sleep disturbances and neurovegetative component. However, the presence in the same component of suicide ideation and insomnia items comfort the accruing evidence that sleep disturbance and sleep loss signal increase risk for suicidal behaviors (Bernert and Joiner, 2007). For instance, insomnia was found to be an independent predictor of suicidal behavior in depressed patients (Agargun et al., 2007).

In addition to show that the use of suicide items or dimensional components of scales primarily designed to measure depression truly reflects patients' suicidal ideation, we showed that suicide items from self-report measures (BDI-SF) or from clinicians based assessment (HAMD-D17) both correlated with suicide ideations. These results seem to contradict Newport et al. (2007) who suggested that clinician based rating scales may provide only limited information of suicide behavior and Hammad et al. who didn't get an agreement between spontaneously reported suicidal ideation and suicide item ratings on clinicians rating scales (Hammad et al., 2006), possibly because these rating scales were proposed at set times and might have not well captured the targeted events. Interestingly, the setting in which HAM-D17 ratings are obtained may have a substantial effect on ratings. In this study, patients were obtained from a sample admitted to emergency room because of suicide crisis, so there was presumably little reason or ability for patients to deny suicidality as assessed in item 3 of HAM-D17. Subjects in out-patient clinical trials may well deny stigmatized suicidal ideas and behaviors causing Type II error (false negatives). This difference between clinician and self-report assessments regarding suicidality has been found across many years with higher levels of false negatives in clinician ratings than in self-report assessments (Greist et al., 1973; Levine et al., 1989; Vitiello et al., 2009). Clinician raters in clinical trials may also be biased against finding suicidality if suicidality is an exclusion criterion for participation in a clinical trial. These phenomena may partially explain the disagreement between findings in this study and findings in studies by Newport et al. (2007) and Hammad et al. (2006).

Although our protocol was not designed to study the prediction of suicidal act, interestingly, the correlation between the poor course of suicidal behaviors (repeated suicide attempts and early age at onset) and the suicide items of both the HAM-D17 and the BDI-SF suggests that subjects at highrisk of suicide have a propensity to have a high score on the suicide item of these two depression scales. In addition, it suggests that these single items might perceptibly capture additional or different information than the Factor 2 derived from the HAM-D17 PCA.

While clinicians are being asked to give a prediction about hours or days, the majority of the studies revealed that there is almost no predictive power even when high-risk patients are followed for years (Chiles and Strosahl, 2005; Goldstein et al., 1991; Pokorny, 1983). Few exceptions are the studies realized by Brown et al. and Oquendo et al. showing respectively that total score at SSI, BDI or HAM-D17 were risk factors for suicide in psychiatry outpatients (Brown et al., 2000) and that among other factors history of suicide attempt and subjective rating of the severity of depression 
predicted suicidal acts with an additive effect (Oquendo et al., 2004).

It results that it seems highly difficult for a clinician to prevent a behavior that cannot be accurately predicted (Wenzel et al., 2008). Consequently several alternatives have been proposed to search objective markers of suicide risk such as biological markers (Mann et al., 2006) and behavioral markers (Nock et al., 2010). An alternative might be to use a component that summarizes not only the suicidal ideation but also the other symptoms that might load in the suicide prediction. This is a potentially promising approach since this component has been found on clinician-rated scales and on a self-report questionnaire (Uher et al., 2008). This suggestion should be tested now in a follow-up approach.

Since the current strategies using clinical scales failed at predicting suicidal attempts, and that suicidal ideations correlates with the Factor 2 derived from HAM-D17 PCA, the clinical usefulness of suicidal ideation measures should be reconsidered at the individual level.

However, at the population level, given that $90 \%$ of unplanned and $60 \%$ of planned first attempts occurred within 1 year of the onset of ideation (Kessler et al., 1999), suicidal ideation seems to weigh in the suicide process. Consequently, a refinement of the correlates of suicidal ideations could lead to a better comprehension of the unpredictability of these important but sometimes labile thoughts. For instance, studies should characterize the suicide ideation, the suicide plan and the suicide attempts by considering them three separate stages along a continuous process.

\subsection{Limitations}

Our study faces several limitations. First this is a crosssectional study and further studies should be prospective and follow-up studies. Second, our sample was heterogeneous with patients suffering from various psychological conditions leading to suicidal behaviors, such as mood disorders and borderline personality disorders. Future studies should refine the taxonomy of the suicidal behavior in a specific sub-population. Third, suicide item on the HAM-D17 span from no SI to passive SI to suicidal acts, and, on the BDI span from no SI to "I would kill myself if I had a chance." These are qualitatively quite different from the SSI items. We recognize these qualitative differences and we highlight the findings of the present paper since single item approach is one of the most commonly used in the literature. Fourth, training clinicians to perform semi-structured HAM-D17 assessments reliably is challenging (Kobak et al., 2009). In that study it was found that 92\% of HAM-D17 item rating disagreements were attributable to interviewer variability and only $8 \%$ to patient variability. Further, sustainability of HAM-D17 rater training was difficult with $42 \%$ of raters qualified after extensive training no longer qualified a year later despite performing continued HAM-D17 assessments over that interval. Given that, self-report suicidality assessments must be fully structured and may have smaller Type II error while clinician suicidality assessments based on semistructured item 3 of the HAM-D17 are more variable and less reliable over time. Future studies should control for the regular training of clinicians in to perform semi-structured HAM-D17 assessments.

\section{Conclusion}

In this study, we expanded on past research by showing that the use of a single item suicide or a dimensional factor derived from a depression scale might be a valid approach to assess suicidal ideations. In addition, we showed that both self-report measures and clinician based rating scales are useful and correlate with suicidal ideations. These results bear upon some clinical importance since they suggest that suicidal ideations can be consistently assessed by using depression scales.

\section{Role of funding source}

Funding for this study was provided by a FNRS-FRS (National Funds for Scientific Research of Belgium) grant to MD. This research also was supported by grants from Institut National de la santé et de la Recherche Médicale (INSERM), the CHU of Montpellier (PHRC UF 7653) and Agence Nationale de la Recherche (NEURO 2007-GENESIS). Additional supports come from the Jean and Madeleine Vachoux foundation. Those sponsors had no further role in the study design; in the collection, analysis and interpretation of data; in the writing of the report; and in the decision to submit the paper for publication.

\section{Conflict of interest}

All other authors declare that they have no conflicts of interest.

\section{Acknowledgments}

The authors would also like to thank Brianna Bakow, B.A., Massachusetts General Hospital, for her contribution as an outside reviewer.

\section{References}

Agargun, M.Y., Besiroglu, L., Cilli, A.S., Gulec, M., Aydin, A., Inci, R., Selvi, Y., 2007. Nightmares, suicide attempts, and melancholic features in patients with unipolar major depression. Journal of Affective Disorders 98, 267-270

Bagby, R.M., Ryder, A.G., Schuller, D.R., Marshall, M.B., 2004. The Hamilton Depression Rating Scale: has the gold standard become a lead weight? The American Journal of Psychiatry 161, 2163-2177.

Beck, A.T., Beck, R.W., 1972. Screening depressed patients in family practice. A rapid technic. Postgraduate Medicine 52, 81-85.

Beck, A.T., Steer, R.A., 1993. Beck Depression Inventory Manual. Psychological Corporation, San Antonio.

Beck, A.T., Ward, C.H., Mendelson, M., Mock, J., Erbaugh, J., 1961. An inventory for measuring depression. Archives of General Psychiatry 4, 561-571.

Beck, A.T., Kovacs, M., Weissman, A., 1979. Assessment of suicidal intention: the Scale for Suicide Ideation. Journal of Consulting and Clinical Psychology 47, 343-352.

Beck, A.T., Brown, G.K., Steer, R.A., 1997. Psychometric characteristics of the Scale for Suicide Ideation with psychiatric outpatients. Behaviour Research and Therapy 35, 1039-1046.

Bernert, R.A., Joiner, T.E., 2007. Sleep disturbances and suicide risk: A review of the literature. Neuropsychiatric Disease and Treatment 3, 735-743.

Brown, G., 2002. A Review of Suicide Assessment Measures for Intervention Research with Adults and Older Adults. University of Pennsylvania, Philadelphia, PA.

Brown, G.K., Beck, A.T., Steer, R.A., Grisham, J.R., 2000. Risk factors for suicide in psychiatric outpatients: a 20 -year prospective study. Journal of Consulting and Clinical Psychology 68, 371-377.

Busch, K.A., Fawcett, J., Jacobs, D.G., 2003. Clinical correlates of inpatient suicide. The Journal of Clinical Psychiatry 64, 14-19.

Chiles, J.A., Strosahl, K.D., 2005. Clinical Manual for Assessment and Treatment of Suicidal Patients. American Psychiatric Publishing, Arlington, VA.

Elkin, I., Shea, M.T., Watkins, J.T., Imber, S.D., Sotsky, S.M., Collins, J.F., Glass, D.R., Pilkonis, P.A., Leber, W.R., Docherty, J.P., et al., 1989. National Institute of Mental Health Treatment of Depression Collaborative Research Program. General effectiveness of treatments. Archives of General Psychiatry 46, 971-982 discussion 983. 
Goldstein, R.B., Black, D.W., Nasrallah, A., Winokur, G., 1991. The prediction of suicide. Sensitivity, specificity, and predictive value of a multivariate model applied to suicide among 1906 patients with affective disorders. Archives of General Psychiatry 48, 418-422.

Greist, J.H., Gustafson, D.H., Stauss, F.F., Rowse, G.L., Laughren, T.P., Chiles, J.A., 1973. A computer interview for suicide-risk prediction. The American Journal of Psychiatry 130, 1327-1332.

Hamilton, M., 1960. A rating scale for depression. Journal of Neurology, Neurosurgery \& Psychiatry 23, 56-62.

Hammad, T.A., Laughren, T., Racoosin, J., 2006. Suicidality in pediatric patients treated with antidepressant drugs. Archives of General Psychiatry 63, 332-339.

Kessler, R.C., Borges, G., Walters, E.E., 1999. Prevalence of and risk factors for lifetime suicide attempts in the National Comorbidity Survey. Archives of General Psychiatry 56, 617-626.

Kobak, K.A., Brown, B., Sharp, I., Levy-Mack, H., Wells, K., Ockun, F., Williams, J.B., 2009. Sources of unreliability in depression ratings. Journal of Clinical Psychopharmacology 29, 82-85.

Korszun, A., Moskvina, V., Brewster, S., Craddock, N., Ferrero, F., Gill, M., Jones, I.R., Jones, L.A., Maier, W., Mors, O., Owen, M.J., Preisig, M., Reich, T., Rietschel, M., Farmer, A., McGuffin, P., 2004. Familiality of symptom dimensions in depression. Archives of General Psychiatry 61, 468-474.

Levine, S., Ancill, R.J., Roberts, A.P., 1989. Assessment of suicide risk by computer-delivered self-rating questionnaire: preliminary findings. Acta Psychiatrica Scandinavica 80, 216-220.

Mann, J.J., Currier, D., Stanley, B., Oquendo, M.A., Amsel, L.V., Ellis, S.P., 2006 Can biological tests assist prediction of suicide in mood disorders? The International Journal of Neuropsychopharmacology/Official Scientific Journal of the Collegium Internationale Neuropsychopharmacologicum (CINP) 9, 465-474.

Melartin, T.K., Rytsala, H.J., Leskela, U.S., Lestela-Mielonen, P.S., Sokero, T.P., Isometsa, E.T., 2004. Severity and comorbidity predict episode duration and recurrence of DSM-IV major depressive disorder. The Journal of Clinical Psychiatry 65, 810-819.

Meyer, R.E., Salzman, C., Youngstrom, E.A., Clayton, P.J., Goodwin, F.K., Mann, J.J., Alphs, L.D., Broich, K., Goodman, W.K., Greden, J.F., Meltzer, H.Y., Normand, S.L., Posner, K., Shaffer, D., Oquendo, M.A., Stanley, B., Trivedi, M.H., Turecki, G., Beasley Jr., C.M., Beautrais, A.L., Bridge, J.A., Brown, G.K., Revicki, D.A., Ryan, N.D., Sheehan, D.V., 2010. Suicidality and risk of suicide-definition, drug safety concerns, and a necessary target for drug development: a consensus statement. The Journal of Clinical Psychiatry 71 , e1-e21.

Newport, D.J., Levey, L.C., Pennell, P.B., Ragan, K., Stowe, Z.N., 2007. Suicidal ideation in pregnancy: assessment and clinical implications. Archives of Women's Mental Health 10, 181-187.

Nock, M.K., Borges, G., Bromet, E.J., Alonso, J., Angermeyer, M., Beautrais, A., Bruffaerts, R., Chiu, W.T., de Girolamo, G., Gluzman, S., de Graaf, R., Gureje, O., Haro, J.M., Huang, Y., Karam, E., Kessler, R.C., Lepine, J.P., Levinson, D., Medina-Mora, M.E., Ono, Y., Posada-Villa, J., Williams, D., 2008. Crossnational prevalence and risk factors for suicidal ideation, plans and attempts. The British Journal of Psychiatry 192, 98-105.

Nock, M.K., Park, J.M., Finn, C.T., Deliberto, T.L., Dour, H.J., Banaji, M.R., 2010 Measuring the suicidal mind: implicit cognition predicts suicidal behavior. Psychological Science 21, 511-517.

Oquendo, M.A., Galfalvy, H., Russo, S., Ellis, S.P., Grunebaum, M.F., Burke, A., Mann, J.J., 2004. Prospective study of clinical predictors of suicidal acts after a major depressive episode in patients with major depressive disorder or bipolar disorder. The American Journal of Psychiatry 161, 1433-1441.

Perroud, N., 2011. Suicidal ideation during antidepressant treatment: do genetic predictors exist? CNS Drugs 25 (6), 459-471.

Perroud, N., Aitchison, K.J., Uher, R., Smith, R., Huezo-Diaz, P., Marusic, A., Maier, W., Mors, O., Placentino, A., Henigsberg, N., Rietschel, M., Hauser, J., Souery, D., Kapelski, P., Bonvicini, C., Zobel, A., Jorgensen, L., Petrovic, A., Kalember, P., Schulze, T.G., Gupta, B., Gray, J., Lewis, C.M., Farmer, A.E., McGuffin, P., Craig, I., 2009a. Genetic predictors of increase in suicidal ideation during antidepressant treatment in the GENDEP project. Neuropsychopharmacology 34 (12), 2517-2528.

Perroud, N., Uher, R., Marusic, A., Rietschel, M., Mors, O., Henigsberg, N., Hauser, J., Maier, W., Souery, D., Placentino, A., Szczepankiewicz, A., Jorgensen, L., Strohmaier, J., Zobel, A., Giovannini, C., Elkin, A., Gunasinghe, C., Gray, J., Campbell, D., Gupta, B., Farmer, A.E., McGuffin, P., Aitchison, K.J., 2009b. Suicidal ideation during treatment of depression with escitalopram and nortriptyline in genome-based therapeutic drugs for depression (GENDEP): a clinical trial. BMC Medicine 7, 60.

Perroud, N., Uher, R., Ng, M.Y., Guipponi, M., Hauser, J., Henigsberg, N., Maier, W., Mors, O., Gennarelli, M., Rietschel, M., Souery, D., Dernovsek, M.Z., Stamp, A.S., Lathrop, M., Farmer, A., Breen, G., Aitchison, K.J., Lewis, C.M., Craig, I.W., McGuffin, P., 2010. Genome-wide association study of increasing suicidal ideation during antidepressant treatment in the GENDEP project. Pharmacogenomics. doi:10.1038/tpj.2010.70.

Pokorny, A.D., 1983. Prediction of suicide in psychiatric patients. Report of a prospective study. Archives of General Psychiatry 40, 249-257.

Shafer, A.B., 2006. Meta-analysis of the factor structures of four depression questionnaires: Beck, CES-D, Hamilton, and Zung. Journal of Clinical Psychology 62, 123-146.

Shaw, P.J.A., 2003. Multivariate Statistics for the Environmental Sciences. Hodder-Arnold, London.

Sheehan, D.V., Lecrubier, Y., Sheehan, K.H., Amorim, P., Janavs, J., Weiller, E., Hergueta, T., Baker, R., Dunbar, G.C., 1998. The Mini-International Neuropsychiatric Interview (M.I.N.I.): the development and validation of a structured diagnostic psychiatric interview for DSM-IV and ICD-10. The Journal of Clinical Psychiatry 59 (Suppl. 20), 22-33 quiz 34-57.

Sokero, T.P., Melartin, T.K., Rytsala, H.J., Leskela, U.S., Lestela-Mielonen, P.S., Isometsa, E.T., 2003. Suicidal ideation and attempts among psychiatric patients with major depressive disorder. The Journal of Clinical Psychiatry $64,1094-1100$.

Uher, R., Farmer, A., Maier, W., Rietschel, M., Hauser, J., Marusic, A., Mors, O., Elkin, A., Williamson, R.J., Schmael, C., Henigsberg, N., Perez, J., Mendlewicz, J., Janzing, J.G., Zobel, A., Skibinska, M., Kozel, D., Stamp, A.S., Bajs, M., Placentino, A., Barreto, M., McGuffin, P., Aitchison, K.J., 2008. Measuring depression: comparison and integration of three scales in the GENDEP study. Psychological Medicine 38, 289-300.

Vitiello, B., Silva, S.G., Rohde, P., Kratochvil, C.J., Kennard, B.D., Reinecke, M.A., Mayes, T.L., Posner, K., May, D.E., March, J.S., 2009. Suicidal events in the Treatment for Adolescents With Depression Study (TADS). The Journal of Clinical Psychiatry 70, 741-747.

Wenzel, A., Brown, G.K., Beck, A.T., 2008. Cognitive Therapy for Suicidal Patients: Scientific and Clinical Applications. American Psychological Association (APA), Washington, DC. 